\title{
Ex vivo intestinal perfusion model for investigating mucoadhesion of microcontainers
}

Mosgaard, Mette Dalskov; Strindberg, Sophie; Abid, Zarmeena; Petersen, Ritika Singh; Thamdrup, Lasse Højlund Eklund; Andersen, Alina Joukainen; Keller, Stephan Sylvest; Müllertz, Anette; Nielsen, Line Hagner; Boisen, Anja

Published in:

International Journal of Pharmaceutics

Link to article, DOI:

10.1016/j.ijpharm.2019.118658

Publication date:

2019

Document Version

Peer reviewed version

Link back to DTU Orbit

Citation (APA):

Mosgaard, M. D., Strindberg, S., Abid, Z., Petersen, R. S., Thamdrup, L. H. E., Andersen, A. J., Keller, S. S., Müllertz, A., Nielsen, L. H., \& Boisen, A. (2019). Ex vivo intestinal perfusion model for investigating mucoadhesion of microcontainers. International Journal of Pharmaceutics, 570, [118658]. https://doi.org/10.1016/j.jpharm.2019.118658

\section{General rights}

Copyright and moral rights for the publications made accessible in the public portal are retained by the authors and/or other copyright owners and it is a condition of accessing publications that users recognise and abide by the legal requirements associated with these rights.

- Users may download and print one copy of any publication from the public portal for the purpose of private study or research.

- You may not further distribute the material or use it for any profit-making activity or commercial gain

- You may freely distribute the URL identifying the publication in the public portal 


\section{Journal Pre-proofs}

Ex vivo intestinal perfusion model for investigating mucoadhesion of microcontainers

Mette D. Mosgaard, Sophie Strindberg, Zarmeena Abid, Ritika Singh Petersen, Lasse H.E. Thamdrup, Alina J. Andersen, Stephan Sylvest Keller, Anette Müllertz, Line Hagner Nielsen, Anja Boisen

PII: S0378-5173(19)30703-3

DOI: https://doi.org/10.1016/j.ijpharm.2019.118658

Reference: $\quad$ IJP 118658

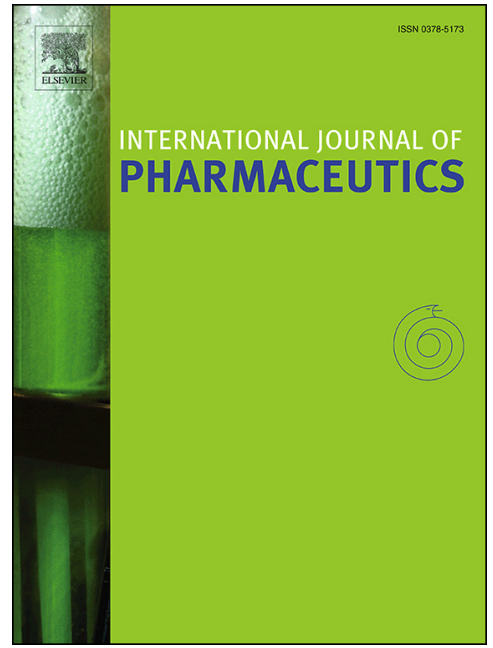

To appear in: International Journal of Pharmaceutics

Received Date: $\quad 8$ July 2019

Revised Date: $\quad 29$ August 2019

Accepted Date: $\quad 31$ August 2019

Please cite this article as: M.D. Mosgaard, S. Strindberg, Z. Abid, R. Singh Petersen, L.H.E. Thamdrup, A.J. Andersen, S. Sylvest Keller, A. Müllertz, L. Hagner Nielsen, A. Boisen, Ex vivo intestinal perfusion model for investigating mucoadhesion of microcontainers, International Journal of Pharmaceutics (2019), doi: https://doi.org/ 10.1016/j.ijpharm.2019.118658

This is a PDF file of an article that has undergone enhancements after acceptance, such as the addition of a cover page and metadata, and formatting for readability, but it is not yet the definitive version of record. This version will undergo additional copyediting, typesetting and review before it is published in its final form, but we are providing this version to give early visibility of the article. Please note that, during the production process, errors may be discovered which could affect the content, and all legal disclaimers that apply to the journal pertain.

(C) 2019 Published by Elsevier B.V. 


\section{Ex vivo intestinal perfusion model for investigating mucoadhesion of microcontainers}

Mette D. Mosgaard ${ }^{*}$, Sophie Strindberg, Zarmeena Abid, , Ritika Singh Petersen, Lasse H. E. Thamdrup ${ }^{a}$, Alina J. Andersen ${ }^{a}$, Stephan Sylvest Keller ${ }^{c}$, Anette Müllertz ${ }^{b}$, Line Hagner Nielsen ${ }^{a}$ and Anja Boisen $^{a}$

aDepartment of Health Technology, Technical University of Denmark, Ørsteds Plads 345C, 2800 Kgs. Lyngby, Denmark ${ }^{b}$ Department of Pharmacy, Faculty of Health and Medical Sciences, University of Copenhagen, Universitetsparken 2, 2100 Copenhagen, Denmark

'National Center of Nano Fabrication and Characterization, DTU Nanolab, Technical University of Denmark, Ørsteds Plads 345C, 2800 Kgs. Lyngby, Denmark

\section{*Corresponding author:}

E-mail address: medmo@dtu.dk (Mette D. Mosgaard), Department of Health Technology, Technical University of Denmark, Ørsteds Plads 345C, 2800 Kgs. Lyngby, Denmark.

Abbreviations: poly- $\varepsilon$-caprolactone (PCL), Fasted State Simulated Intestinal Fluid (FaSSIF), silicon (Si), Poly(vinyl alcohol) (PVA), Landrace x Yorkshire x Duroc (LYD), Scanning electron microscope (SEM), High performance liquid chromatography (HPLC). 


\begin{abstract}
$\underline{\text { Abstract }}$
Micro fabricated delivery systems have shown promise in increasing oral bioavailability of drugs. Micrometer-sized polymeric devices (microcontainers) have the potential to facilitate unidirectional drug release directly into the intestinal mucosa whereby, drug absorption can be enhanced. The aim of this study was to develop an ex vivo model to investigate mucosal adhesion and orientation of microcontainers. Furthermore, to investigate how microcontainers with varying height, shape and material behave in regards to mucoadhesion and orientation. Microcontainers were placed at the top of an inclined piece of porcine small intestine. The tissue was perfused with biorelevant medium followed by microscopic examination to observe the orientation and amount of microcontainers on the tissue. The mucoadhesion of the microcontainers were evaluated based on the observed position on the tissue after being exposed to flow. When comparing the varying types of microcontainers, good adhesion was in general observed since most of the microcontainers were located in the beginning of the intestine. Microcontainers fabricated from the epoxy-based photoresist SU-8 had a slightly better adherence than those fabricated from poly- $\varepsilon$-caprolactone (PCL). The orientation of the microcontainers appeare to be dictated mainly by the height. In general, the model showed promising results in evaluating mucoadhesion and orientation.
\end{abstract}

\title{
$\underline{\text { Keywords }}$
}

Microdevices, microcontainers, oral drug delivery, ex vivo intestinal perfusion, mucoadhesion 


\section{Introduction}

Oral administration is the preferred route for drugs, as it offers low production costs and high patient compliance due to self-administration (Liu, 1997; Thanki et al., 2013). However, oral administration has various limitations and challenges. Numerous physiological parameters in the gastrointestinal tract such as a harsh acidic gastric environment in the fasted state, digestive enzymes and a highly viscous mucus layer have shown to compromise the oral bioavailability of many drugs (Sjögren et al., 2014; Zhou, 1994). One strategy to overcome some of these challenges is to use microdevices as oral drug delivery systems (Nielsen et al., 2018). Several studies have shown an increased oral bioavailability of pharmaceuticals when using these platforms (Chirra et al., 2014a; Mazzoni et al., 2017; Nielsen et al., 2016). Microcontainers are one type of such microdevices. These are micrometer-sized hollow shapes, fabricated in polymeric materials with an inner cavity for drug storage (Nielsen et al., 2014, 2012). Only one side of the microcontainer is open, allowing unidirectional drug release. Coating of the open cavity with an enteric polymer can provide protection against the acidic environment as well as enzymatic degradation in the stomach and allow for release in the small intestine (Nielsen et al., 2016). Unidirectional release is believed to result in an increased local drug concentration at the intestinal wall (Ainslie et al., 2009; Nielsen et al., 2018). This is, however, only possible if the unidirectional release is occurring directly into the mucus layer. Another advantage of using microcontainers as an oral drug delivery system is that polydispersity can be avoided. The fabrication technique allows for very precise sizes and shapes of the microcontainers enabling uniform drug loading.

There are many possibilities for changing and optimising microcontainers to achieve a direct drug release into the mucus layer. The fabrication technique of the microcontainers make them a very flexible and versatile drug delivery system (Ahmed et al., 2002; Chirra and Desai, 2012; Tao et al., 2007). Previous studies have shown that e.g. size, shape and material of polymeric carriers affect their behaviour and performance in in vivo settings (Champion et al., 2007; Pereira de Sousa et al., 2015). The surface chemistry of polymeric drug carriers for oral delivery has been extensively studied, as it has been demonstrated to influence the interaction between the polymeric carrier and the mucosal surface, hence drug absorption (Champion et al., 2007; Pereira de Sousa et al., 2015). Furthermore, the size of the polymeric carriers influences flow properties, clearance and degradation in the mucus layer in the small intestine (Dunne et al., 2000; Patil et al., 2001). Few studies have investigated nanosized polymeric carriers with different shapes, and it is believed that shape differences will affect the movement of these carriers when exposed to a flow (Champion and Mitragotri, 2009). The above mentioned studies have been conducted on nanoparticles. However, the same parameters can be important for microcontainers and their behaviour in the small intestine (Chirra et al., 2014b). 
Previously, it has been reported from in situ and in vivo studies in rats that the microcontainers embed deeply into the intestinal mucus layer, resulting in increased absorption and thereby, enhanced oral bioavailability of ketoprofen and of an amorphous sodium salt of furosemide when compared to controls using the free drug (Mazzoni et al., 2017; Nielsen et al., 2016). These results have shown that dosing of a drug in microcontainers can indeed increase oral bioavailability. This is believed to be associated with an enhanced mucoadhesion of the microcontainers.

In rats, the size ratio (small intestinal diameter in rats $0.3-0.5 \mathrm{~cm}$ and in human $5 \mathrm{~cm}$ ) between the intestinal lumen and the microcontainers is significantly smaller than in humans (Kararli, 1995). To provide a better in vitro/in vivo correlation of how the microcontainers are interacting and orientating themselves in the intestinal mucus layer in humans, the size ratio should be larger (Swindle et al., 2012). Using intestinal tissue from pigs (small intestinal diameter 2.5-3.5 cm) is one way to achieve this, as the size ratio is more similar to human intestine (Kararli, 1995). Furthermore, humans and pigs have comparable digestive processes as well as similar viscoelastic properties of their mucus layer (Lai et al., 2009).

Many well documented methods have investigated ex vivo mucoadhesion. One of these has been developed by Rao and Buri, who used an open piece of small intestine from a rat to measure bioadhesiveness of coated particles (Rao and Buri, 1989). This method has been modified by others to test e.g. mucoadhesion of a dual-sided planar macro device, spray dried chitosan particles and nanoparticles (Lee et al., 2016; Madsen et al., 2013; Nielsen et al., 1998). Many of the studies use the same setup but the experimental parameters such as the angle of the tissue, flow rate, tissue size and duration of the experiments are varying and depends on the formulations being investigated. The drawback of this approach is that the tissue is cut open, and the mucus layer is thereby exposed to stress and the realistic in vivo setting of the intestine is lost. When opening the intestinal tissue the mucus layer will be affected by hydration which will change the viscoelastic properties and ionic strength of the mucus (Lieleg and Ribbeck, 2011). The parameters used in this study has been inspired by perfusion studies conducted in situ on rat intestine and in general from physiological conditions in pigs. The flow rate was e.g. calculated in relation to the size ratio between a rat and pig intestine (Sinko et al., 1995). Fabiano et al. have developed another simple setup for testing mucoadhesion of nanoparticles with an applied water flow through a mucus layer (Fabiano et al., 2017). However, this setup is limited by the size of the drug delivery systems as larger microdevices, such as microcontainers, are less affected by the water flow through the mucus layer compared to nanoparticles. The developed models lack the information on how microcontainers will orient themselves in the intestine and how they perform when exposed to a flow in the lumen.

Another very important aspect of testing microcontainers and their behaviour ex vivo is to evaluate drug release profiles. Methods to improve mucoadhesion of microcontainers, such as using mucoadhesive surfaces, must not compromise the release profile. Therefore, evaluation of the drug release profile from microcontainers is a desirable feature in a new model. 
The aim of this study was to develop and evaluate a novel ex vivo porcine intestinal perfusion model to test mucoadhesion and orientation of microcontainers. Four types of microcontainers were tested and compared with respect to height, shape and material. Also, drug concentration was measured over time in the perfused fluid, and a drug release profile from the microcontainers was recorded. These investigations served two purposes: evaluation of (1) the porcine ex vivo small intestinal perfusion model and (2) microcontainer behaviour when exposed to the porcine ex vivo small intestinal perfusion model.

\section{Materials and methods}

\subsection{Materials}

Fasted State Simulated Intestinal Fluid (FaSSIF) powder was purchased from Biorelevant.com, (London, UK). Monobasic sodium phosphate dehydrate, sodium chloride, acetonitrile anhydrous 99.8\%, trichloroacetic acid 99.0\%, poly-e-caprolactone (PCL) $(\mathrm{Mn}=80,000 \mathrm{~g} / \mathrm{mol})$ and paracetamol were all acquired from Sigma-Aldrich (St. Louis, USA). Trifluoroacetic acid $\geq$ 99.9\% was obtained from Carl Roth ${ }^{\circledR}$ (Karlsruhe, Germany) and gelatine capsules size 9 were purchased from Torpac ${ }^{\circledR}$ (Fairfield, USA). Stainless steel Spectra/Mesh ${ }^{\circledR}$ woven filters with a mesh opening of $213 \mu \mathrm{m}$ and a thickness of $178 \mu \mathrm{m}$ were from Spectrum ${ }^{\circledR}$ Labs.com (CA, USA). Poly(vinyl alcohol) (PVA) Mowiflex C17 was kindly provided by Kuraray (Tokyo, Japan). Silicon (Si) wafers 4-inch (100) single-side polished were obtained from Topsil (Frederikssund, Denmark), whereas SU-8 2035, 2075 and SU-8 developer were purchased from Microresist Technology GmbH (Berlin, Germany). The 3D printed components used in the custom-made setup were made from polylactic acid (PLA) and polyethylene terephthalate glycol (PETG), which were obtained from Devil Design (Ryszka Mateja Sp. J., Poland).

\subsection{Fabrication of SU-8 and PCL microcontainers}

Microcontainers with different heights and shapes were fabricated in two different materials (Table 1). SU-8 cylindrical microcontainers were fabricated as previously described with two steps of conventional mask-based photolithography on a silicon $(\mathrm{Si})$ wafer with a fluorocarbon coating deposited by plasma polymerisation (Keller et al., 2007; Nielsen et al., 2016). This allowed for dry release of individual microcontainers from the support substrate (Keller et al., 2007). The triangular microcontainers were fabricated in a similar fashion but the UV exposure was conducted with a maskless aligner. The dimensions of the various microcontainers are shown in Table 1 and were characterized using an optical profiler (PLu Neox 3D Optical Profiler from Sensofar, Spain) as well as optical microscopy (Nikon Eclipse L200, NY USA). After fabrication, the wafer was cut into squared chips using a dicing saw (DISCO, automatic dicing saw, DAD 321, Japan). Each chip of cylindrical microcontainers contained 625 microcontainers and had a size of $12.8 \times 12.8 \mathrm{~mm}$. Chips of triangular microcontainers contained 625 microcontainers and had a size of $25 \times 25 \mathrm{~mm}$. 
Microcontainers in the biodegradable polymer PCL were fabricated by a hot punching process as previously described (Abid et al., 2019; Petersen et al., 2015). These microcontainers were fabricated on a water soluble PVA substrate containing 1,600 microcontainers. To obtain individual microcontainers, the whole substrate was soaked into water and stirred at 1,200 rpm for $35 \mathrm{~min}$ to dissolve the PVA, leaving only the free floating PCL microcontainers. The microcontainers were then filtered with a woven stainless steel filter and dried at $37{ }^{\circ} \mathrm{C}$ before further use.

\subsection{Drug loading and capsule filling}

Only the high SU-8 microcontainers were loaded with paracetamol as model drug and compared with empty high microcontainers. The drug loading procedure was performed as described previously by Abid et al. (Abid et al., 2017). A silicon chip with 625 microcontainers was gently placed in a holder and a shadow mask was aligned to the cavities of the microcontainers. Paracetamol powder was distributed with a brush across the shadow mask thereby, loading the cavities of the microcontainers. Afterwards, the mask was gently removed and excess drug in between the microcontainers was removed with pressurised air. The chip was weighed before and after loading to determine the amount of drug loaded into the microcontainers.

The four microcontainer types (both with and without paracetamol) were filled into gelatine capsules. The capsules were weighed before and after filling to determine the amount of microcontainers in one capsule.

\section{$\underline{2.4 \text { Visualisation of microcontainers }}$}

The height, shape and dimensions of the different microcontainers and the loading quality of the high microcontainers were investigated using scanning electron microscope (SEM) (TM3030Plus Tabletop Microscope, Hitachi ${ }^{\circledR}$, Tokyo, Japan). The inspection was done using the SE detector and an acceleration voltage of $15 \mathrm{kV}$ to obtain high quality images.

\subsection{Porcine small intestinal ex vivo perfusion model}

The ex vivo study was conducted at the Department of Health Technology at the Technical University of Denmark under the license number DK-10-13-oth-736416. The Department of Experimental Medicine, University of Copenhagen, kindly donated the small intestine from Landrace $x$ Yorkshire $x$ Duroc (LYD) pigs. The pigs were 15-16 weeks of age and the weight was $50-55 \mathrm{~kg}$. The small intestine was cut into pieces with a length of approximately $18 \mathrm{~cm}$ and stored at $-20^{\circ} \mathrm{C}$ until further use.

A specially designed setup, including a humidity chamber and tissue holder, was developed and fabricated for these experiments (Fig. 1) (Vaut et al., 2019). A heating lamp was placed inside the sealed chamber and was programmed to maintain a temperature of $37 \pm 1.1^{\circ} \mathrm{C}$. A humidifier was also located inside the chamber to keep the humidity high and stable. The tissue holder was fabricated in glycol-modified polyethylene and was $19.5 \mathrm{~cm}$ long and $3.3 \mathrm{~cm}$ in width. In one 
end of the tissue holder, a small connector was attached to a tube, which was connected to a peristaltic pump (Watson Marlow 120S/DV, Falmouth, UK). From the connector, the holder was narrowed $(11.8 \mathrm{~mm})$ to be able to fasten a piece of porcine small intestine. The tissue holder can be set at different angles to change the position of the tissue. A self-constructed filter holder with a woven stainless steel filter with a pore size of $213 \mu \mathrm{m}$ was placed underneath the exit of the intestine. A custom-made auto sampler was also developed for sampling the perfused fluid over time.

\subsection{Perfusion experiments}

Perfusion experiments were conducted in the designed setup. Two hours prior to an experiment, FaSSIF was prepared at $\mathrm{pH} 6.5$ and kept at $37^{\circ} \mathrm{C}$ until further use. An $18 \mathrm{~cm}$ long piece of small intestine from a pig was thawed for 30-50 min at room temperature followed by immediately placing and fastening it to the tissue holder. Then, the tissue was placed at an angle of $20^{\circ}$ in the pre-heated chamber with an average humidity during the experiment of $60.9 \pm 11.5 \%$ (Nielsen et al., 1998). Next, the intestine was flushed with FaSSIF for $15 \mathrm{~min}(4.1 \mathrm{~mL} / \mathrm{min})$ to remove all residues. After the washing procedure, the tissue holder was placed at an angle of $10^{\circ}$ and flushed for $5 \mathrm{~min}(1.55 \mathrm{~mL} / \mathrm{min})$ to obtain a water rich environment for dissolving the microcontainer-filled capsule. A capsule filled with microcontainers was then placed approximately $2 \mathrm{~cm}$ from the start of the intestine. After $15 \mathrm{~min}$, the tissue holder was placed back at an angle of $20^{\circ}$ and a flow of FaSSIF $1.55 \mathrm{~mL} / \mathrm{min}$ was initiated (Sinko et al., 1995). After 30 min of perfusion, the tissue holder was gently removed and the tissue was detached from the holder. The piece of tissue was then cut into pieces with a length of approximately 2 $\mathrm{cm}$, opened and divided into sections named start, middle, end and exit (each section consists of three pieces except for the exit part which is the microcontainers found on the filter). The tissue was placed onto microscope glass slides and dried in air for approximately $1 \mathrm{~h}$ before visualisation on a microscope (see section 2.7). The number of microcontainers in each piece was counted and their orientation was noted. The orientation of the microcontainers was classified as: (I) sideways, (II/III) with bottom up/down or (IV) deeply embedded into the mucus layer (Fig. 2). A microcontainer was defined as lying 'sideways' when the open side of container was placed facing horizontally into the mucus layer, partly or fully embedded in the mucus layer. The orientation 'bottom up/down' was used when the open cavity of a container was facing towards the mucus or out towards the lumen of the intestine.

For the paracetamol-loaded microcontainers, samples were taken at different time intervals from the perfused fluid to investigate the drug concentration over time. Samples were taken after 1, 5, $10,15,20,25$ and 29 min and the samples were collected for $1 \mathrm{~min}$ to receive approximately $1.55 \mathrm{~mL}$. The first sample was collected from flow initiation to $1 \mathrm{~min}$ after initiation.

\subsection{Fluorescence and light microscopy of the microcontainers on the intestinal tissue}


Fluorescence microscopy was used to locate and visualise the microcontainers fabricated in SU8. A U-RFL-T mercury/xenon burner was utilised with a U-LH100HG microscope (Olympus ${ }^{\circledR}$, Tokyo, Japan), and CellSens Entry software (version 1.12, Olympus ${ }^{\circledR}$, Tokyo, Japan) was used to take images of the microcontainers. A DAPI filter was employed to identify the SU-8 microcontainers in the mucus layer as well as clarifying the orientation of them.

A light microscope (Zeiss Axio Scope.A1, Carl Zeiss, Göttingen, Germany) with a C-DIC filter and AxioVision SE64 software (version 4.9.1 SP1) was used for visualising the PCL microcontainers on the intestine.

\subsection{High performance liquid chromatography (HPLC) for quantification of paracetamol}

The amount of paracetamol in the perfused fluid over time was determined by UV-detection on a HPLC (Shimadzu, Kyoto, Japan). Protein precipitation in the samples was conducted with $10 \%$ $(\mathrm{w} / \mathrm{v})$ trichloroacetic acid in a 1:1 ratio. The samples were centrifuged at 14,000 rpm for $10 \mathrm{~min}$ and analysed on the HPLC.

The HPLC system was equipped with a SIL-20AC HT automated sample injector and a SPDM20A photodiode array detector. LabSolutions Lite (version 5.82) software was employed to analyse the data (shimadzu, Kyoto, Japan), and paracetamol was detected at $250 \mathrm{~nm}$ with a reverse-phase Kinetix ${ }^{\circledR} \mathrm{C} 18$ column with the dimensions of 100 x 4.6 mm $\left(\right.$ Phenomenex $^{\circledR}$, Torrance, CA, USA). The mobile phase consisted of $95 \%(\mathrm{v} / \mathrm{v})$ trifluoroacetic acid $0.1 \%(\mathrm{v} / \mathrm{v})$ and $5 \%(\mathrm{v} / \mathrm{v})$ acetronitrile with isocratic elution. The flow rate was $0.5 \mathrm{~mL} / \mathrm{min}$ with an injection volume of $20 \mu \mathrm{L}$. The retention time was 6.6 min and paracetamol was quantified using a standard calibration curve in the linear range of $0.5-75 \mu \mathrm{g} / \mathrm{mL}$.

\section{$\underline{\text { 2.9 Statistics }}$}

All data presented in this study are expressed as mean \pm standard deviation (SD). Statistical analysis was carried out using Student t-tests in GraphPad Prism version 7.04 (CA, USA). Pvalues below $5 \%(\mathrm{p}<0.05)$ were considered statistically significant.

\section{Results and discussion}

The developed porcine ex vivo small intestinal model can provide information on mucoadhesion, orientation of microcontainers and drug release profiles.

\subsection{Microcontainer characterization}

SEM images show the design of the four types of microcontainers (Fig. 3). The different design parameters are listed in Table 1.

The differences in shapes, heights and material resulted in different weights of the microcontainers (Table 1). The shape, height, material and thereby also weight of the 
microcontainers are believed to play a role in how the microcontainers are behaving in the small intestine, and this could influence the mucoadhesion.

\subsection{Mucoadhesion of microcontainers}

The mucoadhesion of the microcontainers was evaluated based on the observed position of the microcontainers on the intestinal tissue (Fig. 4). The movement of the microcontainers is an estimate of how mucoadhesive the microcontainers are. The longer they move in the intestine the less adhesive they are. The high and low microcontainers were in general behaving very similar (Fig. 4A), and significantly more were found in the start of the intestine (77.6 $\pm 25.1 \%$ and 80.8 $\pm 12.9 \%$, respectively) compared to the other sections. However, there was a tendency that more high microcontainers were found in the middle $(19.5 \pm 22.6 \%)$ of the intestine when compared to the low microcontainers $(9.7 \pm 5.6 \%)$. More of the low microcontainers were observed to exit $(5.8 \pm 7.3 \%)$ the intestine than the high microcontainers $(1.8 \pm 2.0 \%)$. When comparing the adhesion abilities of the tri and low microcontainers (Fig. 4B), there were again significantly more microcontainers found in the start of the intestine $(67.1 \pm 13.8 \%$ and $80.8 \pm 12.9 \%$, respectively) compared to the other sections. Significantly, more of the tri microcontainers were observed in the middle section compared to the low microcontainers $(\mathrm{P}=0.049)$. Only small amounts of the tri and low microcontainers were observed in the end and exit section. The data indicates that the tri microcontainers adhered less in the start of the intestine as more of the microcontainers had moved to the middle section. When comparing the adhesion abilities of PCL and SU-8 microcontainers with the same height (Fig. 4C), the SU-8 microcontainers seem more adhesive. A larger number of PCL microcontainers were observed in the sections further down the intestine, whereas the low SU-8 microcontainers were more abundant in the start of the intestine. Significantly more of the PCL and low microcontainers were found in the start of the intestine $(65.0 \pm 14.2 \%$ and $80.8 \pm 12.9 \%$, respectively) compared to the other sections.

In general, all the different types of microcontainers showed good adhesion properties. Between $65-81 \%$ of the microcontainers were located in the start of the intestine. However, the graphs indicate variations between the microcontainers' ability to adhere to the mucosal surface. The high microcontainers seemed to adhere more to the intestinal surface as their movement practically stopped after reaching the middle part of the intestine. In contrast, more of the low microcontainers, that were not adhering in the beginning, moved all the way through the intestine and were found to exit the intestine. The high microcontainers have a larger surface that can adhere to mucus and, in addition, they are heavier than the low microcontainers, which could result in increased adhesion. The height of microcontainers is believed to influence how they adhere to the mucosal surface. Thick microdevices have been reported to increase the shear forces, per mass, and to be more likely to dislodge themselves from a mucosal surface when exposed to flow conditions (Chirra and Desai, 2012). However, this effect was not observed in our model for the high microcontainers. When comparing the tri and low microcontainers, it was expected that the triangular shaped microcontainers would adhere more to the mucosal surface than the cylindrical shaped due to the sharp edges. These two types of microcontainers had 
similar weight but significantly different shapes. The data suggest that the tri microcontainers adhere less in the start section and adhere more in the middle section as compared to the low microcontainers. This suggests that tri microcontainers moved easier with the flow at the beginning, but the sharp edges also made it more likely for them to adhere to the surface in the middle.

There was a tendency that the PCL microcontainers were adhering less to the mucosal surface than the SU-8 microcontainers of similar height. The chemical structure of the two polymers can affect the microcontainers' ability to adhere to the mucus layer. SU-8 is a very hydrophobic polymer and can create numerous hydrophobic interactions with mucus (Abgrall et al., 2007). PCL is believed to interact less with mucus as it is less hydrophobic, thus, SU-8 might be more mucoadhesive when compared to PCL (Norris and Sinko, 1997; Sigurdsson et al., 2013).

Another factor that can influence the tendency of the PCL microcontainers to adhere less to the mucosal surface than the SU-8 microcontainers is there weight difference. The PCL microcontainers had a weight of $3.7 \pm 0.4 \mu \mathrm{g}$ which make them significantly lighter than the low SU-8 microcontainers with a weight of $7.5 \pm 0.1 \mu \mathrm{g}$. This might make the PCL microcontainers more prone to move with a continuous flow. This aspect was difficult to circumvent since the weight will be affected when changing either the height, shape or material.

One possible explanation for the lack of significant difference between the ability of the different microcontainers to adhere to the mucosal surface could be physiological variations of the tissue. The model has been simplified to limit the amount of affecting parameters meaning that the intestinal segment in this model is lacking motility and presence of food. Moreover, the amount of fluid is constant, and all the parameters are rarely the case in vivo. Further studies are needed to clarify the effect of such parameters.

One challenge, with this setup and when working with microcontainers, is to achieve an acceptable recovery. The recovery is an estimate of the amount of microcontainers added to an experiment and how many of the microcontainers that can be found again. However, this experimental setup enabled good results in this regard, as the average recovery for all the experiments was above $75 \%$. Table 2 states the recovery of the different microcontainers which indicates the capability of the model.

\subsection{Orientation of microcontainers}

Several studies have emphasized the importance of controlling the direction of drug release from microdevices (Ahmed et al., 2002; Ainslie et al., 2009; Chirra et al., 2014b). Most drug delivery systems have omni-directional drug release which results in a loss of drug into the lumen. This will reduce the drug absorption into the systemic circulation and thereby, the oral bioavailability. By achieving a unidirectional release from microcontainers directly into the mucus layer, one would expect an increased drug absorption (Chirra et al., 2014a; Chirra and Desai, 2012). Microcontainers oriented sideways (I) or with the open cavity up (II) or down (III) are illustrated in Fig. 5. It was uncertain to distinguish between cavity facing up or down, and these microcontainers were therefore grouped together. 
The orientation of all the microcontainers found in the different sections of the intestine on the mucosal surface is shown in Fig. 6. The high microcontainers were mainly lying sideways (I) (P $=0.0006)$ and showed a significant difference compared to the low microcontainers that were primarily oriented with the cavity up or down (II)/(III) $(\mathrm{P}=0.001)$. No significant difference was observed when looking at the amount of high and low microcontainers found deeply embedded (IV) into the mucus layer (Fig. 6A). When comparing the orientation of the tri and low microcontainers, no significant differences were observed (Fig. 6B), and both tri and low microcontainers were primarily lying with the cavity up or down (II)/(III). Significantly more of the SU-8 microcontainers (low) were oriented sideways (I) when compared to the PCL microcontainers $(\mathrm{P}=0.03)$. However, significantly more of the PCL microcontainers were oriented with the cavity up or down (II)/(III) $(\mathrm{P}=0.003)$. PCL microcontainers could not be seen as clearly as SU-8 microcontainers when embedded deeply in mucus. SU-8 is autoflorescent, and this is not the case for PCL. Therefore, microcontainers located deep in the mucus layer was not included in Fig. 6C.

The data indicated that the height of the microcontainers was a dominant factor in determining the orientation of the microcontainers, compared to shape and material. From the results obtained, it is clear that the microcontainers with low height were more prone to adhere with the cavity up or down (II)/(III), while the high microcontainers were lying sideways (I).

The data for the high microcontainers showed that $60 \pm 12 \%$ of the microcontainers were lying sideways (I) (partly embedded) and $13 \pm 6 \%$ were deeply embedded (IV) into mucus. This means that approximately $73 \%$ of the microcontainers were orientated with the open cavity very close to the mucus layer and could deliver drug directly into the mucus layer. The amount could most likely be even higher, as $26 \pm 8 \%$ of the microcontainers are lying with the cavity up or down (II)/(III). If it is assumed that half of these were oriented with the cavity down, it resulted in approximately $86 \%$ of the high microcontainers releasing the drug into the mucus layer. If the same assumption is done with the low microcontainers then $66 \%$ of the microcontainers would be oriented with the open cavity very close to the mucus layer and could deliver drug directly into the layer. These indications state how important it is to evaluate the orientation of the microcontainers as further optimization might not be needed to increase the oral bioavailability. These results correlated well with the results obtained in previous in vivo studies with the microcontainers, where an increased oral bioavailability was obtained when using high microcontainers (Nielsen et al., 2016). Another advantage of the high microcontainers is that they have a high loading capacity compared to more planar microdevices (Chirra et al., 2014b; Nielsen et al., 2018).

\subsection{Drug loaded microcontainers}

The model developed in this study can provide information about the drug release profile from the microcontainers. The high microcontainers were loaded with paracetamol to investigate the 
effect of loading the microcontainers with a drug. The average paracetamol loading capacity for each microcontainer was $3.1 \pm 1.1 \mu \mathrm{g}(\mathrm{n}=3000)$ and paracetamol-loaded microcontainers are shown in Fig. 7A. The loaded microcontainers were compared to empty high microcontainers to investigate how these microcontainers moved in the intestine when exposed to a constant flow (Fig. 7B). As can be seen in Fig. 7B was their ability to adhere to the intestinal surface similar. The orientation of the drug-loaded microcontainers was also similar to the empty ones (Fig. 7C). The drug-loaded microcontainers were mainly oriented sideways. It was possible to measure the concentration of paracetamol in the perfused fluid over time. The highest drug concentration was measured as soon as the flow was initiated, followed by decreasing drug concentrations over time, and after $21 \mathrm{~min}$ there was no drug present in the samples (Fig. 7D). This was expected since paracetamol is highly water soluble and is easily released from the microcontainers in an aqueous environment (Shaw et al., 2005; Szałek et al., 2011).

\section{Conclusion}

In this work, a porcine ex vivo small intestinal perfusion model for evaluation of mucoadhesion and orientation of microcontainers was developed. The model is a promising alternative to wellestablished mucoadhesion models and is suitable for investigating microdevices. The model showed promising results in evaluating mucoadhesion, orientation and the drug release profile of microcontainers. Comparisons of microcontainers with different height, shape and material properties were carried out both to evaluate the porcine ex vivo small intestinal perfusion model and to identify parameters affecting mucoadhesion and orientation of the microcontainers. In general, all the different types of microcontainers showed good adhesion properties, as they were mainly located in the start of the intestine. The orientation of the microcontainers was mainly controlled by the height of the microcontainers and was less affected by shape and material. Loading the microcontainers with paracetamol did not affect the orientation nor the mucoadhesion. These results indicate that the microcontainers fabricated from SU-8 are mucoadhesive, which is in line with the in vivo results obtained in previous studies. However, when changing the material of the microcontainers to a more biodegradable polymer, such as PCL, one might need to improve the mucoadhesion with surface modifications to control the orientation of the microcontainers.

\section{Acknowledgment}

The authors would like to acknowledge the Danish National Research Foundation (DNRF122) and Villum Fonden (Grant No. 9301) for Intelligent Drug Delivery and Sensing Using Microcontainers and Nanomechanics (IDUN). The authors would also like to acknowledge Nanna Bild, Department of Health Technology, Technical University of Denmark, for the illustrations. The authors would also like to acknowledge Lukas Vaut, Department of Health Technology, Technical University of Denmark for designing, developing and constructing the partly $3 \mathrm{D}$ printed ex vivo retention model setup featuring a tissue holder, a temperature and humidity-controlled chamber and a remotely controlled rotary sampler. 


\section{References}

Abgrall, P., Conedera, V., Camon, H., Gue, A.-M., Nguyen, N.-T., 2007. SU-8 as a structural material for labs-on-chips and microelectromechanical systems. Electrophoresis 28, 45394551. https://doi.org/10.1002/elps.200700333

Abid, Z., Gundlach, C., Durucan, O., von Halling Laier, C., Nielsen, L.H., Boisen, A., Keller, S.S., 2017. Powder embossing method for selective loading of polymeric microcontainers with drug formulation. Microelectron. Eng. 171, 20-24. https://doi.org/10.1016/J.MEE.2017.01.018

Abid, Z., Strindberg, S., Javed, M.M., Mazzoni, C., Vaut, L., Nielsen, L.H., Gundlach, C., Petersen, R.S., Müllertz, A., Boisen, A., Keller, S.S., 2019. Biodegradable microcontainers - towards real life applications of microfabricated systems for oral drug delivery. Lab Chip 19, 2905-2914. https://doi.org/10.1039/C9LC00527G

Ahmed, A., Bonner, C., Desai, T.A., 2002. Bioadhesive microdevices with multiple reservoirs: a new platform for oral drug delivery. J. Control. Release 81, 291-306. https://doi.org/10.1016/S0168-3659(02)00074-3

Ainslie, K.M., Lowe, R.D., Beaudette, T.T., Petty, L., Bachelder, E.M., Desai, T.A., 2009. Microfabricated Devices for Enhanced Bioadhesive Drug Delivery: Attachment to and Small-Molecule Release Through a Cell Monolayer Under Flow. Small 5, 2857-2863. https://doi.org/10.1002/smll.200901254

Champion, J.A., Katare, Y.K., Mitragotri, S., 2007. Particle shape: A new design parameter for micro- and nanoscale drug delivery carriers. J. Control. Release 121, 3-9. https://doi.org/10.1016/J.JCONREL.2007.03.022

Champion, J.A., Mitragotri, S., 2009. Shape Induced Inhibition of Phagocytosis of Polymer Particles. Pharm. Res. 26, 244-249. https://doi.org/10.1007/s11095-008-9626-z

Chirra, H.D., Desai, T.A., 2012. Multi-Reservoir Bioadhesive Microdevices for Independent Rate-Controlled Delivery of Multiple Drugs. Small 8, 3839-3846. https://doi.org/10.1002/smll.201201367

Chirra, H.D., Shao, L., Ciaccio, N., Fox, C.B., Wade, J.M., Ma, A., Desai, T.A., 2014a. Planar Microdevices for Enhanced In Vivo Retention and Oral Bioavailability of Poorly Permeable Drugs. Adv. Healthc. Mater. 3, 1648-1654. https://doi.org/10.1002/adhm.201300676

Chirra, H.D., Shao, L., Ciaccio, N., Fox, C.B., Wade, J.M., Ma, A., Desai, T.A., 2014b. Planar Microdevices for Enhanced In Vivo Retention and Oral Bioavailability of Poorly Permeable Drugs. Adv. Healthc. Mater. 3, 1648-1654. https://doi.org/10.1002/adhm.201300676

Dunne, M., Corrigan, O.I., Ramtoola, Z., 2000. Influence of particle size and dissolution conditions on the degradation properties of polylactide-co-glycolide particles. Biomaterials 21, 1659-1668. https://doi.org/10.1016/S0142-9612(00)00040-5

Fabiano, A., Zambito, Y., Bernkop-Schnürch, A., 2017. About the impact of water movement on the permeation behaviour of nanoparticles in mucus. Int. J. Pharm. 517, 279-285. https://doi.org/10.1016/j.ijpharm.2016.12.024

Kararli, T.T., 1995. Comparison of the gastrointestinal anatomy, physiology, and biochemistry of humans and commonly used laboratory animals. Biopharm. Drug Dispos. 16, 351-380. https://doi.org/10.1002/bdd.2510160502

Keller, S., Haefliger, D., Boisen, A., 2007. Optimized plasma-deposited fluorocarbon coating for dry release and passivation of thin SU-8 cantilevers. Cit. J. Vac. Sci. Technol. B Microelectron. Nanom. Struct. Process. 25, 1903. https://doi.org/10.1116/1.2806960 
Lai, S.K., Wang, Y.-Y., Wirtz, D., Hanes, J., 2009. Micro- and macrorheology of mucus. Adv. Drug Deliv. Rev. 61, 86-100. https://doi.org/10.1016/J.ADDR.2008.09.012

Lee, Y.-A.L., Zhang, S., Lin, J., Langer, R., Traverso, G., 2016. A Janus Mucoadhesive and Omniphobic Device for Gastrointestinal Retention. Adv. Healthc. Mater. 5, 1141-1146. https://doi.org/10.1002/adhm.201501036

Lieleg, O., Ribbeck, K., 2011. Biological hydrogels as selective diffusion barriers. Trends Cell Biol. 21, 543-551. https://doi.org/10.1016/j.tcb.2011.06.002

Liu, G., 1997. Patient preferences for oral versus intravenous palliative chemotherapy. J. Clin. Oncol. 15.

Madsen, K.D., Sander, C., Baldursdottir, S., Pedersen, A.M.L., Jacobsen, J., 2013. Development of an ex vivo retention model simulating bioadhesion in the oral cavity using human saliva and physiologically relevant irrigation media. Int. J. Pharm. 448, 373-381. https://doi.org/10.1016/J.IJPHARM.2013.03.031

Mazzoni, C., Tentor, F., Strindberg, S.A., Nielsen, L.H., Keller, S.S., Alstrøm, T.S., Gundlach, C., Müllertz, A., Marizza, P., Boisen, A., 2017. From concept to in vivo testing:

Microcontainers for oral drug delivery. J. Control. Release 268, 343-351. https://doi.org/10.1016/J.JCONREL.2017.10.013

Nielsen, L.H., Keller, S.S., Boisen, A., 2018. Microfabricated devices for oral drug delivery. Lab Chip 18, 2348-2358. https://doi.org/10.1039/c81c00408k

Nielsen, L.H., Keller, S.S., Boisen, A., Müllertz, A., Rades, T., 2014. A slow cooling rate of indomethacin melt spatially confined in microcontainers increases the physical stability of the amorphous drug without influencing its biorelevant dissolution behaviour. Drug Deliv. Transl. Res. 4, 268-274. https://doi.org/10.1007/s13346-013-0166-7

Nielsen, L.H., Keller, S.S., Gordon, K.C., Boisen, A., Rades, T., Müllertz, A., 2012. Spatial confinement can lead to increased stability of amorphous indomethacin. Eur. J. Pharm. Biopharm. 81, 418-425. https://doi.org/10.1016/j.ejpb.2012.03.017

Nielsen, L.H., Melero, A., Keller, S.S., Jacobsen, J., Garrigues, T., Rades, T., Müllertz, A., Boisen, A., 2016. Polymeric microcontainers improve oral bioavailability of furosemide. Int. J. Pharm. 504, 98-109. https://doi.org/10.1016/j.ijpharm.2016.03.050

Nielsen, L.S., Schubert, L., Hansen, J., 1998. Bioadhesive drug delivery systems: I. Characterisation of mucoadhesive properties of systems based on glyceryl mono-oleate and glyceryl monolinoleate. Eur. J. Pharm. Sci. 6, 231-239. https://doi.org/10.1016/S09280987(97)10004-5

Norris, D.A., Sinko, P.J., 1997. Effect of size, surface charge, and hydrophobicity on the translocation of polystyrene microspheres through gastrointestinal mucin. J. Appl. Polym. Sci. 63, 1481-1492. https://doi.org/10.1002/(SICI)1097-4628(19970314)63:11<1481::AIDAPP10>3.0.CO;2-5

Patil, V.R.S., Campbell, C.J., Yun, Y.H., Slack, S.M., Goetz, D.J., 2001. Particle Diameter Influences Adhesion under Flow. Biophys. J. 80, 1733-1743. https://doi.org/10.1016/S0006-3495(01)76144-9

Pereira de Sousa, I., Steiner, C., Schmutzler, M., Wilcox, M.D., Veldhuis, G.J., Pearson, J.P., Huck, C.W., Salvenmoser, W., Bernkop-Schnürch, A., 2015. Mucus permeating carriers: formulation and characterization of highly densely charged nanoparticles. Eur. J. Pharm. Biopharm. 97, 273-279. https://doi.org/10.1016/J.EJPB.2014.12.024

Petersen, R.S., Keller, S.S., Boisen, A., 2015. Hot punching of high-aspect-ratio 3D polymeric microstructures for drug delivery. Lab Chip 15, 2576-2579. 
https://doi.org/10.1039/C5LC00372E

Rao, K.V.R., Buri, P., 1989. A novel in situ method to test polymers and coated microparticles for bioadhesion. Int. J. Pharm. 52, 265-270. https://doi.org/10.1016/0378-5173(89)90229-9

Shaw, L.R., Irwin, W.J., Grattan, T.J., Conway, B.R., 2005. The Effect of Selected WaterSoluble Excipients on the Dissolution of Paracetamol and Ibuprofen. Drug Dev. Ind. Pharm. 31, 515-525. https://doi.org/10.1080/03639040500215784

Sigurdsson, H.H., Kirch, J., Lehr, C.-M., 2013. Mucus as a barrier to lipophilic drugs. Int. J. Pharm. 453, 56-64. https://doi.org/10.1016/j.ijpharm.2013.05.040

Sinko, P.J., Hu, P., Waclawski, A.P., Patel, N.R., 1995. Oral absorption of anti-aids nucleoside analogues. 1. Intestinal transport of didanosine in rat and rabbit preparations. J. Pharm. Sci. 84, 959-965. https://doi.org/10.1002/jps.2600840811

Sjögren, E., Abrahamsson, B., Augustijns, P., Becker, D., Bolger, M.B., Brewster, M., Brouwers, J., Flanagan, T., Harwood, M., Heinen, C., Holm, R., Juretschke, H.-P., Kubbinga, M., Lindahl, A., Lukacova, V., Münster, U., Neuhoff, S., Nguyen, M.A., Peer, A. van, Reppas, C., Hodjegan, A.R., Tannergren, C., Weitschies, W., Wilson, C., Zane, P., Lennernäs, H., Langguth, P., 2014. In vivo methods for drug absorption - Comparative physiologies, model selection, correlations with in vitro methods (IVIVC), and applications for formulation/API/excipient characterization including food effects. Eur. J. Pharm. Sci. 57, 99-151. https://doi.org/10.1016/J.EJPS.2014.02.010

Swindle, M.M., Makin, A., Herron, A.J., Clubb, F.J., Frazier, K.S., 2012. Swine as Models in Biomedical Research and Toxicology Testing. Vet. Pathol. 49, 344-356. https://doi.org/10.1177/0300985811402846

Szałek, E., Kamińska, A., Murawa, D., Połom, K., Urbaniak, B., Sobiech, M., Grześkowiak, E., Grabowski, T., Wolc, A., Kokot, Z.J., Murawa, P., 2011. Comparison of the pharmacokinetics of paracetamol from two generic products in patients after total gastric resection. Pharmacol. Reports 63, 1518-1525. https://doi.org/10.1016/S17341140(11)70715-0

Tao, S.L., Popat, K., Desai, T.A., 2007. Off-wafer fabrication and surface modification of asymmetric 3D SU-8 microparticles. Nat. Protoc. 1, 3153-3158. https://doi.org/10.1038/nprot.2006.451

Thanki, K., Gangwal, R.P., Sangamwar, A.T., Jain, S., 2013. Oral delivery of anticancer drugs: Challenges and opportunities. J. Control. Release 170, 15-40. https://doi.org/10.1016/J.JCONREL.2013.04.020

Vaut, L., Scarano, E., Tosello, G., Boisen, A., 2019. Fully replicable and automated retention measurement setup for characterization of bio-adhesion. HardwareX 6, e00071. https://doi.org/10.1016/J.OHX.2019.E00071

Zhou, X.H., 1994. Overcoming enzymatic and absorption barriers to non-parenterally administered protein and peptide drugs. J. Control. Release 29, 239-252. https://doi.org/10.1016/0168-3659(94)90071-X 


\section{Tables}

Table 1: Design parameters of the microcontainers used in this study.

\begin{tabular}{|c|c|c|c|c|c|c|}
\hline Name & Shape & Illustration & Material & $\begin{array}{l}\text { Weight } \\
(\mu \mathrm{g})\end{array}$ & $\begin{array}{l}\text { Outer } \\
\text { diameter } \\
(\mu \mathrm{m})\end{array}$ & $\begin{array}{l}\text { Total height } \\
(\mu \mathrm{m})\end{array}$ \\
\hline High & Cylindrical & & SU-8 & $21.1 \pm 1.4$ & $326 \pm 1$ & $257 \pm 4$ \\
\hline Low & Cylindrical & & SU-8 & $7.5 \pm 0.1^{*}$ & $316 \pm 5$ & $108 \pm 11$ \\
\hline Tri & Triangular & & SU-8 & $7.0 \pm 0.6^{*}$ & $368 \pm 4$ & $131 \pm 0.4$ \\
\hline$P C L$ & Cylindrical & & PCL & $3.7 \pm 0.4$ & $304 \pm 3$ & $92.0 \pm 2$ \\
\hline
\end{tabular}

*No significant difference between the weights. P-values below $5 \%(\mathrm{p}<0.05)$ were considered statistically significant.

Table 2: The average recovery \pm SD of the various types of microcontainers $(n=4)$.

\begin{tabular}{ccccc}
\hline & High & Low & Tri & PCL \\
\hline Recovery (\%) & $90.6 \pm 7.4$ & $84.6 \pm 5.2$ & $83.2 \pm 12.1$ & $86.9 \pm 5.3$ \\
\hline
\end{tabular}




\section{Captions}

Fig. 1: Schematic of the ex vivo intestinal perfusion model. A piece of intestinal tissue is placed on an angle adjustable tissue holder (A), which is connected to a tube (B). A gelatine capsule loaded with microcontainers was placed at the top part of the tissue (the inserted box). A filter was placed below the tissue holder (C). An auto sampler with test tubes facilitates sampling of the perfused fluid over time (D).

Fig. 2: Schematic of the microcontainer orientation on the porcine intestinal tissue. (I) sideways, (II) with bottom down, (III) with bottom up and (IV) deeply embedded in the mucus layer.

Fig. 3: SEM images of the four types of microcontainers. A) $257 \pm 4 \mu \mathrm{m}$ in height SU-8 microcontainers. B) $108 \pm 11 \mu \mathrm{m}$ high SU-8 microcontainers. C) $131 \pm 0.4 \mu \mathrm{m}$ high triangular SU-8 microcontainers. D) $92 \pm 2 \mu \mathrm{m}$ high microcontainers fabricated in PCL.

Fig. 4: Percentage of microcontainers located in the start, middle, end and exit of the porcine small intestine after perfusion studies. A) Comparison of microcontainers with a height of $257 \pm$ $4 \mu \mathrm{m}$ (high) and $108 \pm 11 \mu \mathrm{m}$ (low). B) Triangular (tri) and cylindrical (low) shaped microcontainers with similar heights. C) Microcontainers with similar heights fabricated from PCL and SU-8 (low). Data is represented as mean \pm SD with $\mathrm{n}=4$.* indicates significant difference.

Fig. 5: Microscopy images of microcontainers located in the intestinal tissue. A) Image of $257 \pm$ $4 \mu \mathrm{m}$ high microcontainer with a cylindrical shape lying sideways (I). B) $257 \pm 4 \mu \mathrm{m}$ high microcontainer lying up or down (II)/(III). C) Image of microcontainers with a triangular shape with one lying sideways (I) and one lying cavity up or down (II)/(III). D) Four PCL microcontainers lying up or down (II)/(III). A), B), C) Show SU-8 microcontainers investigated with fluorescence microscopy with a DAPI filter and $5 \mathrm{X}$ in magnification. D) Show PCL microcontainers with a light microscope with a C-DIC filter.

Fig. 6: Percentage of microcontainers that were oriented sideways (I), up/down (II)/(III) or deep (IV) in the surface of the porcine small intestine after the perfusion experiment. A) Comparison between $257 \pm 4 \mu \mathrm{m}$ (high) and $108 \pm 11 \mu \mathrm{m}$ (low) high microcontainers. B) Triangular (tri) and cylindrical microcontainers (low). C) PCL and SU-8 (low) microcontainers. Data is represented as mean $\pm \mathrm{SD}$ with $\mathrm{n}=4$. ${ }^{*}$ indicates significant difference.

Fig. 7: A) SEM image of paracetamol-loaded $257 \pm 4 \mu \mathrm{m}$ high SU-8 microcontainers. B) The amount of microcontainers in percent located in the start, middle, end and exit of the porcine 
small intestine after being exposed to a perfusion experiment. Data is represented as mean $\pm \mathrm{SD}$, $\mathrm{n}=4$. C) The amount of microcontainers in percent that were oriented sideways (I), up/down (II)/(III) and deep (IV) in the surface of the porcine small intestine. Data is represented as mean $\pm \mathrm{SD}, \mathrm{n}=4$. D) Graph of the paracetamol concentration as a function of time. Data is represented as mean $\pm \mathrm{SD}, \mathrm{n}=4$. 